\title{
CARACTERIZAÇÃO MECÂNICA DA FASE AUSTENITA DO AÇO INOXIDÁVEL 304L E DA LIGA NiTi RICA EM Ni UTILIZANDO A TÉCNICA DE ULTRAMICRODUREZA INSTRUMENTADA*
}

\author{
Artur Camposo Pereira ${ }^{1}$ \\ Foluke Salgado de Assis ${ }^{2}$ \\ Andersan dos Santos Paula ${ }^{3}$
}

\section{Resumo}

O presente trabalho buscou explorar a aplicação da ultramicrodureza instrumentada na caracterização microestrutural e mecânica de materiais metálicos aço inoxidável 304L e liga NiTi Rica em Ni, ambos no campo austenítico. Para isso foi utilizado um ultramicrodurômetro instrumentado (Shimadzu, modelo DUH-211S) com medidas a temperatura ambiente e distintas cargas máximas e tempos de permanência. De acordo com algumas das possibilidades apresentadas, pode-se concluir que a ultramicrodureza instrumentada é uma ferramenta poderosa para a caracterização mecânica correlacionada aos aspectos microestruturais de materiais metálicos.

Palavras-chave: Ultramicrodureza instrumentada; Propriedades mecânicas; Microestrutura; aço inoxidável austenítico 304L; liga NiTi rica em Ni.

\section{AUSTENITE PHASE MECHANICAL CHARACTERIZATION OF THE 304L STAINLESS STEEL AND Ni-RICH NiTi ALLOY USING THE INSTRUMENTED ULTRAMICROHARDNESS TECHNIQUE}

\section{Abstract}

This study aimed to explore the application of instrumented ultramicrohardness on the microstructural and mechanical characterization of metallic materials $304 \mathrm{~L}$ stainless steel and $\mathrm{Ni}$-Rich $\mathrm{NiTi}$, both in austenitic field. For this was used an instrumented ultramicrohardness (Shimadzu, model DUH-211S) with measures at room temperature and distinct maximum load and creep time. According to the some possibilities presented, the instrumented ultramicrohardness is a powerful tool for the mechanical characterization correlated to the metallic materials microstructural aspects.

Keywords: Instrumented ultramicrohardness; Mechanical properties; Microstructure; 304L austenitic stainless steel; Ni-Rich NiTi alloy.

1 Engenheiro Metalurgista e de Materiais, Mestrando em Ciência dos Materiais (PGCM), Instituto Militar de Engenharia, Rio de Janeiro, RJ, Brasil.

2 Engenheiro Metalurgista e de Materiais, Mestrando em Ciência dos Materiais (PGCM), Instituto Militar de Engenharia, Rio de Janeiro, RJ, Brasil.

3 Engenheira Metalurgista, D.Sc., Professora Adjunta da SE/4 e PGCM, Instituto Militar de Engenharia, Rio de Janeiro, RJ, Brasil; e orientadora credenciada do PPGEM/UFF, Volta Redonda, RJ, Brasil. 


\section{INTRODUÇÃO}

As Transformações Martensíticas em ligas metálicas têm seu início somente quando a temperatura atinge valores abaixo da temperatura de início da transformação martensítica (Mi) ${ }^{(1,2)}$, sendo assim uma "transformação atérmica". Quando este tipo de transformação ocorre em ligas metálicas dotadas de solução sólida com presença significativa de átomos intersticiais, como por exemplo as ligas ferrosas ou aço, os cristais da "fase martensítica" (M) não continuam a crescer depois de formados, pois estes são nucleados individualmente e crescem rapidamente (aproximadamente 1/3 da velocidade de ondas elásticas em sólidos) até encontrar uma barreira (contorno de grão da fase-mãe, precipitados, inclusões, etc). A transformação continua pela nucleação de novos cristais "M" a partir da "fase-mãe" (A) remanescente no material, por decréscimo da temperatura. Sendo assim estes cristais da fase $M$ não voltam a crescer, ou decrescer por variação da temperatura, ou seja, trata-se de uma transformação irreversível, "não-termoelástica".

Nas transformações martensíticas termoelásticas, uma vez nucleados os cristais "M", estes crescem a uma velocidade proporcional à velocidade de resfriamento. Similarmente, o mesmo se aplica aos cristais "A" no aquecimento, tornando a transformação reversível por processo também adifusional.

No entanto, certas ligas metálicas passíveis de transformação martensítica termoelástica ou não termoelásticas podem ter a transformação martensítica induzida pela tensão externa aplicada ao material no campo de temperatura de estabilidade da fase mãe, em regiões próximas e superiores a temperatura final da transformação austenítica (Af). Ou seja, a transformação de fase induzida por plasticidade faz-se presente acima da temperatura $M_{i}$ na qual a formação da martensita é induzida por decréscimo de temperatura.

Para as ligas metálicas passíveis de transformação martensítica não termoelástica este efeito é denominado de transformação induzida por plasticidade (efeito TRIP) (3), a fase mãe se faz estável até em temperaturas redor da ambiente e a temperatura $\mathrm{Mi}_{\mathrm{i}}$ é inferior a esta. São exemplos deste tipo de ligas com este efeito os aços inoxidáveis austeníticos da series 300 e 200.

Por outro lado, as transformações martensíticas termoelásticas ${ }^{(1,2)}$ para além de serem também cruciais na realização do efeito de memória de forma (EMF) e da superelasticidade. Sendo o EMF a capacidade de reverter a forma macroscópica e cristalográfica após a deformação da martensita (por intermédio da demaclagem) pelo aquecimento até a temperatura de final da reversão ao campo da fase mãe (Af). Por outro lado, a superelasticidade deve a capacidade da fase-mãe sob aplicação de tensão de tornar-se instável e transformar-se em martensita, ao remover a tensão aplicada a martensita reverte-se a fase mãe que lhe deu origem, resultando em uma grande recuperação macroscópico e cristalográfica de uma deformação não-linear induzida durante a carga. São exemplos deste tipo de materiais as ligas de NiTi, CuAINi, etc.

O aço Inox 304L é um aço inoxidável austenítico e é passível de transformação de fase induzida por plasticidade (efeito TRIP), ou seja, esse aço possui a capacidade de induzir plasticamente a fase produto martensítica a partir da fase mãe austenítica, em resposta a tensões externas aplicadas numa faixa de temperatura de trabalho, propiciando excelentes propriedades de resistência mecânica ao longo de um processo de deformação plástica associada a uma extensa ductilidade. $\mathrm{O}$ aço Inox 304L é aplicado em indústrias automobilísticas, componentes de usinas nucleares, resistência (corrosão e mecânica), boa ductilidade e soldabilidade. Nesse aço, a fase 
austenítica presente em temperatura ambiente se encontra de maneira metaestável durante o processo de deformação, a qual se transforma em martensita, ou seja, uma microestrutura cúbica de face centrada (CFC) associada a austenita se transforma cúbica de corpo centrado (CCC) que dá origem a martensita ${ }^{(3,4)}$.

As ligas de $\mathrm{Ni}-\mathrm{Ti}$ com uma composição próxima da equiatômica, através do intermetálico NiTi, apresentam o Efeito de Memória de Forma (EMF) e o carácter superelástico (SE) associados à Transformação Martensítica (TM) termoelástica. Sob certas condições, a transformação martensítica pode ocorrer em uma ou duas etapas a partir da fase-mãe (B2 - austenita) formando ou não a fase trigonal com distorção romboédrica com distorção no ângulo alfa (conhecida como fase $R$ ou somente $R$ ) e então para a fase B19' (martensita - monoclínica). Entretanto, muitos são os fatores que contribuem para afetar a estrutura e comportamento dos efeitos de memória de forma e superelasticidade, tais como o teor em $\mathrm{Ni}$, tratamento térmico e termomecânicos, além da adição de elementos de liga e impurezas. Esta liga, na condição rica em $\mathrm{Ni}$ ou equiatômica, é largamente usada em instrumentos médicos e implantes, no qual é requerida a superelasticidade ${ }^{(1,2)}$.

O objetivo deste trabalho, utilizando a técnica de ultramicrodureza instrumentada em comparação com o valor da dureza HV, foi analisar as propriedades mecânicas associando as características microestruturais da fase austenítica (fase-mãe) dos seguintes materiais metálicos: liga NiTi rica em Ni e aço inoxidável austenítico 304L.

\section{MATERIAIS E MÉTODOS}

\subsection{MATERIAIS}

Os materiais analisados nesse trabalho foram uma liga $\mathrm{NiTi}$ rica em $\mathrm{Ni}$ e um aço inoxidável austenítico 304L.

Na Tabela 1 é mostrada a composição química da amostra do aço Inox 304L que foi utilizada no presente trabalho. De acordo com a composição química do aço, as temperaturas $M_{i}$ e $M_{d 30}$ são $-40,89^{\circ} \mathrm{C}$ e $61,72^{\circ} \mathrm{C}$, respectivamente, baseados nas equações (1) e (2).

Tabela 1. Composição química do aço Inox 304L (3).

\begin{tabular}{ccccccccc}
\hline \multicolumn{8}{c}{ Elemento (\% em peso) } \\
\hline $\mathbf{C}$ & $\mathbf{M n}$ & $\mathbf{S i}$ & $\mathbf{P}$ & $\mathbf{S}$ & $\mathbf{C r}$ & $\mathbf{N i}$ & $\mathbf{M o}$ & $\mathbf{A l}$ \\
\hline 0,018 & 1,2693 & 0,4786 & 0,0303 & 0,0015 & 18,364 & 8,0221 & 0,0261 & 0,0032 \\
\hline $\mathbf{C u}$ & $\mathbf{C o}$ & $\mathbf{V}$ & $\mathbf{N b}$ & $\mathbf{P b}$ & $\mathbf{B}$ & $\mathbf{T i}$ & $\mathbf{S a}$ & $\mathbf{W}$ \\
\hline 0,0428 & 0,1015 & 0,0418 & 0,0418 & 0,001 & 0,006 & 0,0018 & 0,0044 & 0,0146 \\
\hline \multicolumn{10}{c}{} & \\
$\mathrm{Mi}\left({ }^{\circ} \mathrm{C}\right)=1305-1665(\% \mathrm{C}+\% \mathrm{~N})-28(\% \mathrm{Si})-33(\% \mathrm{Mn})-42(\% \mathrm{Cr})-61(\% \mathrm{Ni})$ & \\
$\mathrm{Md}_{30}\left({ }^{\circ} \mathrm{C}\right)=413-462(\% \mathrm{C}+\% \mathrm{~N})-9,2(\% \mathrm{Si})-8,1(\% \mathrm{Mn})-13,7(\% \mathrm{Cr})-9,5(\% \mathrm{Ni})-18,5(\% \mathrm{Mo})$
\end{tabular}

A chapa da liga NiTi rica em Ni (50,8at. \%Ni-49,2at. \%Ti, com espessura de 0,7 mm) exibe o efeito de superelasticidade em temperatura ambiente. Na Figura 1 são mostradas as curvas de calorimetria diferencial de varredura (DSC) da liga, podendose observar que a liga NiTi apresenta-se austenítica (fase B2) com uma fração diminuta de fase $\mathrm{R}$ à temperatura ambiente, devido ao valor da temperatura do fim da transformação da fase R para $\mathrm{B} 2\left(27,9^{\circ} \mathrm{C}\right)$ ser menor do que o da temperatura de início da transformação B2 para $\mathrm{R}\left(29,6^{\circ} \mathrm{C}\right)^{(2)}$. 
Os difratogramas de raios- $x$ das amostras são mostrados na Figura 2. Para o aço Inox 304L (Figura 2a) observa-se que a amostra apresenta as fases: austenita e vestígios de martensita. Para a liga NiTi rica em Ni (Figura 2b), além da presença dos picos correspondentes à matriz essencialmente austenítica, indicia também a existência do precipitado $\mathrm{Ni}_{4} \mathrm{Ti}_{3}$ na condição como recebida ${ }^{(2)}$. As micrografias revelam o aspecto microestruturais de ambos os materiais constituídos de grãos poligonais de suas respectivas austenita (Figuras $2 \mathrm{c}$ e $2 \mathrm{~d}$ ), sendo que o aço inoxidável ainda apresenta maclas na sua microestrutura.

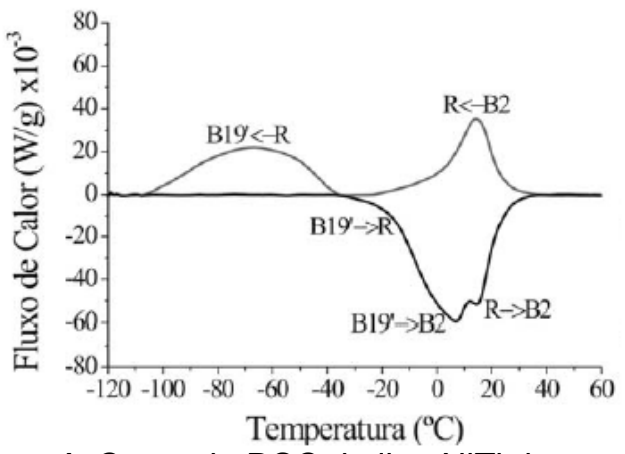

Figura 1. Curva de DSC da liga NiTi rica em $\mathrm{Ni}{ }^{(2)}$
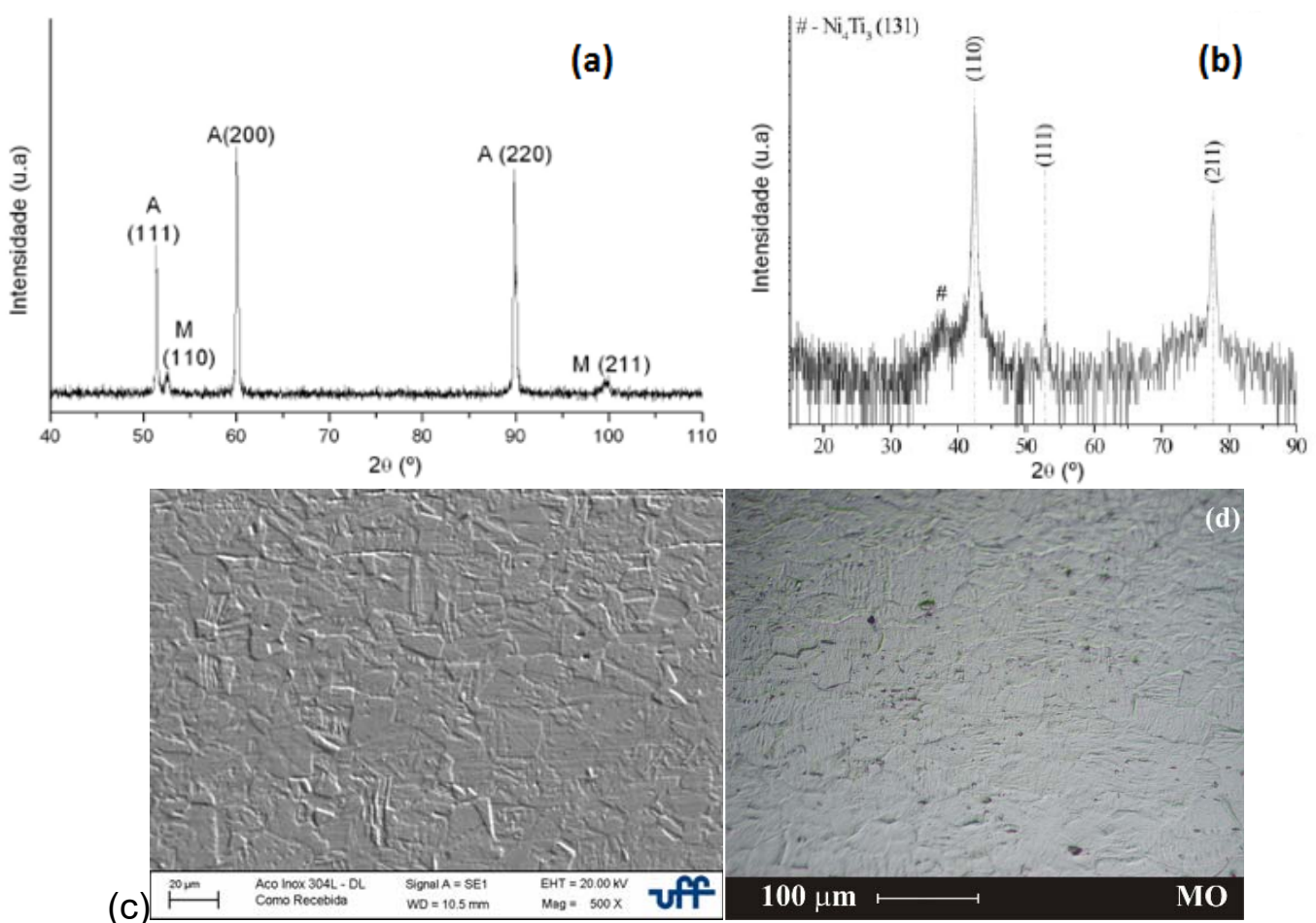

Figura 2. Difratograma de raios- $x$ das amostras $(a, c)$ do aço 304L e (b, d) da liga NiTi rica em Ni. $\mathrm{A}=$ Austenita. $\mathrm{M}=$ Martensita ${ }^{(2,3)}$.

\subsection{MÉTODOS}

Para o ensaio de ultramicrodureza instrumentada foi utilizado um ultramicrodurômetro do fabricante Shimadzu, modelo DUH-211S, controlado pelo software DUH-211S, dotado de um microscópio óptico com câmera digital que permite selecionar pontos da microestrutura associado ao aumento de 500x (50x para objetiva e 10x para ocular). Foram aplicadas nas amostras às cargas máximas de $50 \mathrm{gf}(490 \mathrm{mN}), 100 \mathrm{gf}$ $(980 \mathrm{mN})$ e $200 \mathrm{gf}(1960 \mathrm{mN})$ com tempo de permanência de carga máxima e carga 
mínima de 20 segundos. Foi aplicada também para a carga máxima de $50 \mathrm{gf}$ $(490 \mathrm{mN})$, um tempo de permanência de carga máxima e carga mínima de 120 segundos.

Na Figura 3 é mostrada a curva genérica que relaciona a força aplicada e a profundidade de penetração do indentador na amostra, da qual foi gerada a partir do ensaio de ultramicrodureza instrumentada. A partir deste ensaio, são obtidos valores associados às propriedades do material ensaiado, tais como ${ }^{(5,6)}$ :

- Limite de escoamento com a dureza da indentação $\left(H_{i t}\right)$, de acordo com a Equação (3):

$$
H_{i t}=\frac{F_{\max }}{24,50 h c^{2}}
$$

- Módulo de elasticidade com o módulo da indentação $\left(E_{t}\right)$, de acordo com a Equação (4):

$$
\frac{1}{E_{r}}=\frac{\left(1-v^{2}\right)}{E_{i t}}+\frac{\left(1-v_{i}^{2}\right)}{E_{i}}
$$

- Para materiais metálicos convencionais a ductilidade razão de trabalho elástico com o trabalho total de deformação $\left(n_{t}\right)$, de acordo com a Equação (5):

$$
\eta_{i t}=\frac{\left(W_{\text {elástico }}\right)}{\left(W_{\text {total }}\right)} \times 100
$$

- Dureza dinâmica na carga máxima (DHV-1) que está associada dureza elastoplástica vinculada à profundidade máxima obtida pelo indentador na amostra sob a ação da força máxima, de acordo com a Equação (6):

$$
\text { DHV_1 }=\frac{3,8584 x F_{\max }}{h_{\max }^{2}}
$$

- Dureza dinâmica na carga mínima (DHV-2) que está associada à dureza plástica vinculada a profundidade de indentação relacionada recuperação elástica $\left(\mathrm{h}_{\mathrm{r}}\right)$ com o descarregamento em função da força máxima, de acordo com a Equação (7):

$$
D H V \_2=\frac{3,8584 x F_{\max }}{h_{r}^{2}}
$$

- Dureza Vickers (HV) que é obtida convencionalmente, de acordo com a Equação (8). São medidas as diagonais da indentação, resultante da aplicação da carga máxima ( $\mathrm{P}$ ou Fmax) e sua completa remoção, através da observação por um microscópio óptico que compõe o equipamento:

$$
H V=\frac{1,8544 P}{d^{2}}
$$

É necessário que alguns parâmetros sejam definidos antes do ensaio, tais como [4]: coeficiente de Poisson do material das amostras (liga NiTi e aço Inox $304 \mathrm{~L}=0,33$ ) e tipo de indentador (Vickers), de acordo com a Equação (9):

$$
S=\frac{d P}{d h}=\frac{2 E_{r}\left(24,5 h c^{2}\right)^{0,5}}{\pi^{0,5}}
$$




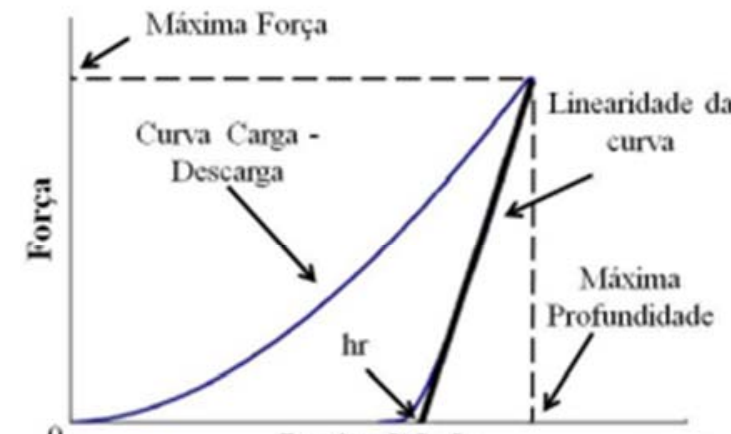

(a)
Profundidade

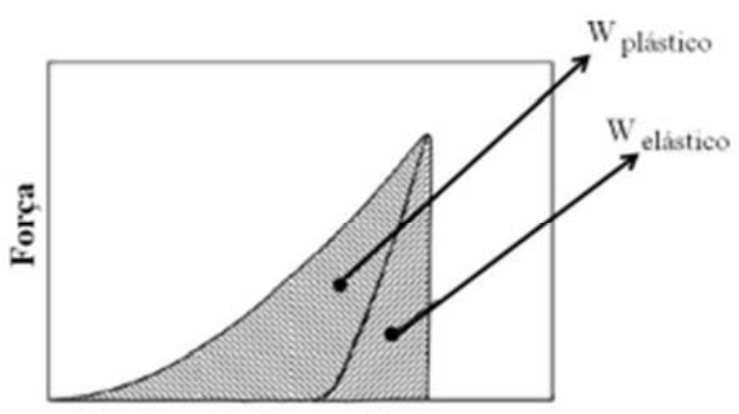

(b)

Profundidade

Figura 3. Curva genérica obtida através do ensaio de ultramicrodureza instrumentada, (a) explicitando as variáveis básicas a serem medidas para cálculo das propriedades e (b) destacando as

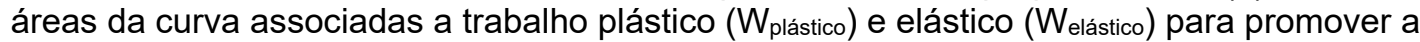
deformação ${ }^{(5)}$.

O trabalho mecânico (W) total indicado durante o procedimento da indentação é somente parcialmente consumido com deformação plástica ( $\mathrm{W}$ plast). Durante a remoção da força de indentação (curva de descarregamento) parte do trabalho é recuperado, ou seja, liberado com deformação reversível ou elástica (Welast). De acordo com a definição de trabalho mecânico ( $\mathrm{W}=\int \mathrm{Fdh}$ ) ambas as partes aparecem em áreas distintas ${ }^{(5,6)}$.

\section{RESULTADOS E DISCUSSÃO}

$\mathrm{Na}$ Figura 4 é mostrada a variação das curvas resultantes dos testes de ultramicrodureza instrumentada nas cargas de $50 \mathrm{gf}(490 \mathrm{mN}), 100 \mathrm{gf}(980 \mathrm{mN})$ e $200 \mathrm{gf}(1960 \mathrm{mN}$ ) para a amostra do aço Inox 304L (Figura 4a) e da liga NiTi (Figura $4 \mathrm{~b}$ ). De acordo com as figuras, para os testes de ultramicrodureza que foram realizados à temperatura ambiente, inicialmente, a liga NiTi encontra-se no campo de fase: B2 (austenita) + fase R; e o aço Inox 304L encontra-se no campo de fase: austenita + martensita, onde em ambos os caso a austenita é a fase majoritária.
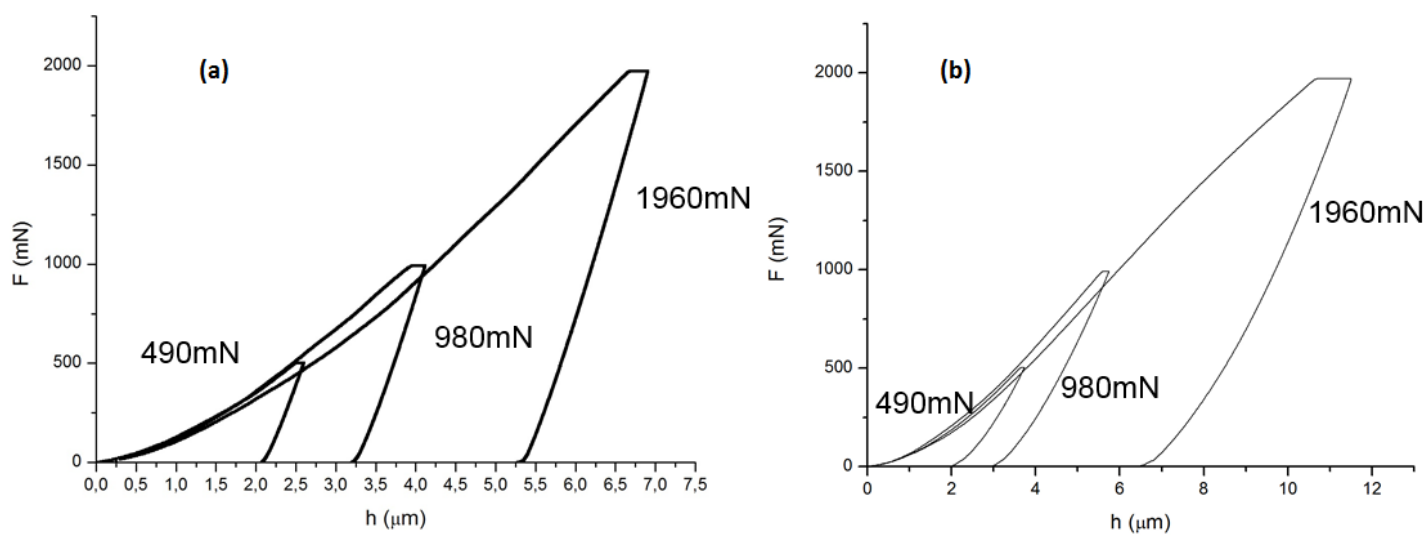

Figura 4. Curva obtida através do ensaio de ultramicrodureza instrumentada do (a) aço Inox 304L e (b) da liga NiTi.

Na Figura 4 é mostrado que durante o carregamento, desde os estágios iniciais de aplicação de carga, que o aço Inox 304L tem um gradiente de profundidade $(\mathrm{h})$ menor que a liga de $\mathrm{NiTi}$, ou seja, para uma certa quantidade de carga aplicada se observa uma menor profundida gerada que indica que uma maior resistência a indentação. Para o gradiente de retorno de carga aplicada, observa-se que a liga NiTi tem um 
maior retorno de profundidade (h) em relação ao aço Inox $304 \mathrm{~L}$. Isso justifica o efeito de superelasticidade presente na liga NiTi e não ao aço Inox 304L.

$\mathrm{Na}$ Figura 5 é mostrada a variação da profundidade de indentação durante a manutenção da carga máxima de $50 \mathrm{gf}(490 \mathrm{mN})$ em função de dois intervalos de tempo (20 s e 120 s) de estabilização de indentação para cada amostra.

Na Figura 5 é retratado que não houve uma estabilização de profundidade $\left(\mathrm{h}_{\mathrm{ti}}-\mathrm{h}_{\mathrm{tf}}\right)$ para o aço Inox 304L e como também para liga NiTi. Isso confirma que em ambos os tempos não foram suficientes para que seja interrompida a deformação e/ou transformação de fase.

$\mathrm{Na}$ Tabela 2 são mostrados os valores extraídos das curvas de indentação ilustradas nesse trabalho. Os valores foram a força máxima aplicada $(\mathrm{mN})$, a profundidade máxima atingida pelo indentador na aplicação da carga, após o término do tempo de permanência na carga máxima (hmax), a profundidade de recuperação associada a região linear a curva de descarregamento (hr), a dureza dinâmica na carga máxima associado a profundidade máxima (DHV-1), a dureza dinâmica na carga máxima (em $\mathrm{mN}$ ) associado a profundidade na carga mínima após descarregamento (DHV-2) e a dureza Vickers (HV).
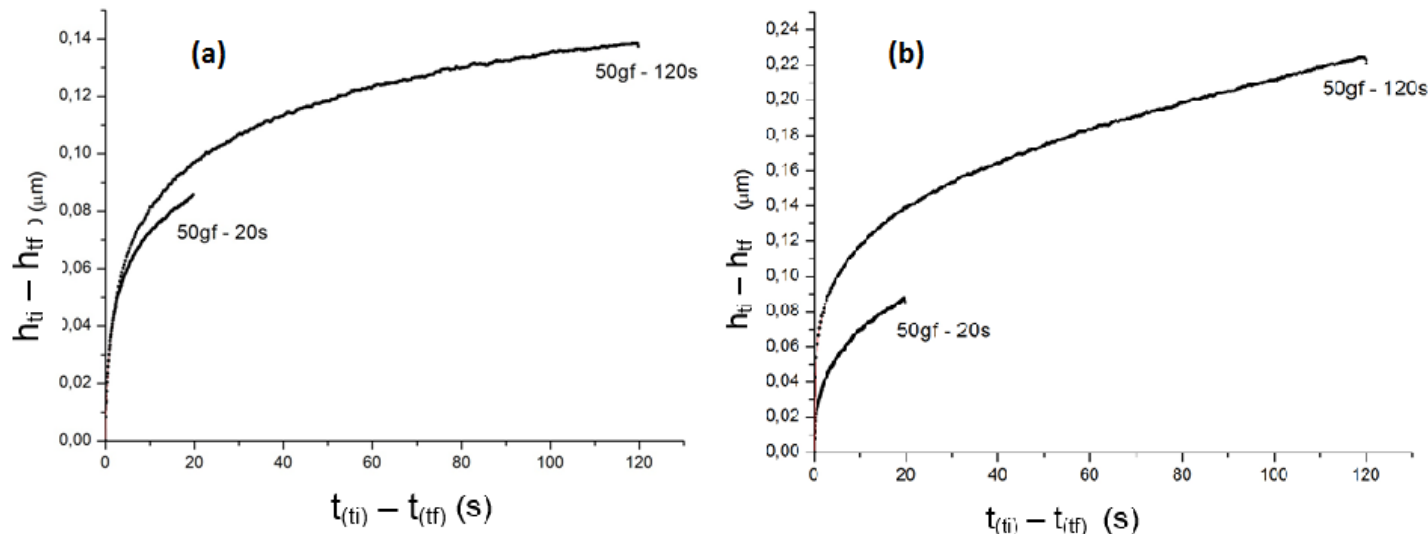

Figura 5. Patamar a carga máxima de $50 \mathrm{gf}(490 \mathrm{mN})$ nos intervalos de tempo (20 s e $120 \mathrm{~s})$ de estabilização de indentação (a) do aço Inox 304L e (b) da liga NiTi.

Tabela 2. Valores das curvas de indentação para o aço Inox 304L e a liga NiTi.

\begin{tabular}{|c|c|c|c|c|c|c|c|c|c|}
\hline & Condições & $\begin{array}{l}F_{\max } \\
(\mathrm{mN})\end{array}$ & $\begin{array}{l}h_{\max } \\
(\mu \mathrm{m})\end{array}$ & $\begin{array}{c}h_{r} \\
(\mu \mathrm{m})\end{array}$ & $\begin{array}{c}\mathbf{h}_{\mathbf{r}} / \\
\mathbf{h}_{\max }\end{array}$ & $\begin{array}{c}\text { DHV-1 } \\
\left(\mathrm{mN} / \mu \mathrm{m}^{2}\right)\end{array}$ & $\begin{array}{c}\text { DHV-2 } \\
\left(\mathrm{mN} / \mu \mathrm{m}^{2}\right)\end{array}$ & $\begin{array}{c}d \\
(\mu \mathrm{m})\end{array}$ & HV \\
\hline \multirow{4}{*}{$\begin{array}{l}\text { Aço } \\
\text { Inox } \\
304 L\end{array}$} & $50 \mathrm{gf}-20 \mathrm{~s}$ & 502,20 & 2,59 & 2,15 & 0,83 & 286,66 & 449,46 & 18,85 & 267,36 \\
\hline & $50 \mathrm{gf}-120 \mathrm{~s}$ & 502,20 & 2,92 & 2,18 & 0,74 & 226,87 & 450,29 & 19,00 & 267,36 \\
\hline & $100 \mathrm{gf}-20 \mathrm{~s}$ & 980,89 & 4,11 & 3,35 & 0,81 & 225,51 & 372,04 & 28,28 & 234,30 \\
\hline & $200 \mathrm{gf}-20 \mathrm{~s}$ & 1971,90 & 6,90 & 5,53 & 0,80 & 159,52 & 272,94 & 39,50 & 239,00 \\
\hline \multirow{4}{*}{$\begin{array}{l}\text { Liga } \\
\text { NiTi }\end{array}$} & $50 \mathrm{gf}-20 \mathrm{~s}$ & 502,35 & 3,73 & 2,51 & 0,67 & 139,13 & 499,73 & 16,90 & 332,46 \\
\hline & $50 \mathrm{gf}-120 \mathrm{~s}$ & 501,96 & 3,49 & 2,54 & 0,72 & 158,95 & 432,00 & 15,11 & 416,04 \\
\hline & $100 \mathrm{gf}-20 \mathrm{~s}$ & 990,99 & 5,74 & 3,71 & 0,64 & 115,92 & 448,94 & 21,70 & 398,14 \\
\hline & $200 \mathrm{gf}-20 \mathrm{~s}$ & 1971,62 & 11,50 & 8,07 & 0,70 & 57,45 & 190,55 & 34,49 & 313,50 \\
\hline
\end{tabular}

De acordo com a Tabela 2, nas amostras do aço Inox 304L e da liga NiTi, a dureza dinâmica elasto-plástica (DHV-1) e plástica (DHV-2) decresceram com o aumento da carga máxima, pois quanto maior a carga aplicada, maior será a profundidade máxima do indentador $\left(h_{\max }\right)$ e a profundidade associada a região linear a curva de descarregamento $\left(h_{r}\right)$, onde esses dois fatores impactam nos valores de DHV-1 
(relacionado a $h_{\max }$ ) e DHV-2 $\left(h_{r}\right)$. Para o aço Inox $304 \mathrm{~L}$, os valores das durezas dinâmicas elasto-plástica apresentaram valores próximos a dureza HV nas condições 50 gf-20 s, 50 gf-120 s, 100 gf-20 s. Entretanto houve uma diferença significativa na condição 200 gf-20 s, a profundidade máxima do indentador ( $h_{\max }$ ) que auxilia no cálculo de DHV-1 aumentou, porém o cálculo de HV leva em conta a área de contato do indentador com a amostra, sendo essa área menor, levando a um maior valor da dureza HV. Para a liga NiTi, a dureza DHV-1 apresentou uma redução mais significativa em relação a HV. Isso ocorre devido a transformação induzida presente na liga $\mathrm{NiTi}$, ou seja, quando há uma aplicação de uma certa carga máxima a profundidade máxima $\left(h_{\max }\right)$ resulta em um maior valor pelo fato das parcelas da deformação vinculada a transformação martensítica e posterior encruamento da região transformada. Já para a dureza DHV-2 teve uma diminuição significativa comparando também com a dureza HV. Como DHV-2 é dividido pela profundidade de indentação relacionada a recuperação elástica $\left(\mathrm{h}_{\mathrm{r}}\right)$, ocorreu uma maior recuperação elástica (menores valores de $\mathrm{h}_{\mathrm{r}} / \mathrm{hmax}$, Tabela 2 ) quando comparado ao aço inox 304L. $\mathrm{Na}$ Tabela 2, para aço Inox 304L nas condições de $50 \mathrm{gf}-20 \mathrm{~s}$ para $100 \mathrm{gf}-20 \mathrm{~s}$, é apresentado um decréscimo da dureza Vickers (HV). Enquanto que nas condições de 100 gf-20 s para 200 gf-20 s, para o aço Inox 304L, observa-se um pequeno incremento em HV. Por outro lado, o comportamento da evolução numérica da dureza HV para a liga de NiTi foi inverso ao do aço Inox 304L. No teste de ultramicrodureza, o carregamento é aumentado paulatinamente até que o máximo valor seja alcançado, independente da resposta da deformação do material e a dureza HV é a relação entre o máximo carregamento e a média das diagonais da impressão da indentador após sua completa remoção. Este comportamento pode estar associada a fração de martensita formada nas zonas de deformação resultantes da penetração do indentador ao longo do ensaio, e bem como da orientação cristalográfica do(s) grão(s) de austenita nesta região que pode:

- no aço Inox 304L - vir a favorecer ou não uma maior fração de martensita e menor encruamento da austenita em função da temperatura do material na região ensaiada. - na liga de $\mathrm{NiTi}$ - estar associada a somente grãos de austenita ou o misto de fase$\mathrm{R}$, para além favorecer ou não a transformação de fase induzida por tensão seguida ou não de um encruamento significativo da martensita formada.

$\mathrm{Na}$ Tabela 3 são mostrados os valores da profundidade atingida pelo indentador ao fim do descarregamento na carga mínima aplicada, após o término do tempo de permanência na carga mínima $\left(h_{p}\right)$, a energia total $\left(W_{t}\right)$, a energia recuperável $\left(W_{e}\right)$ e a energia dissipada $\left(W_{p}\right)$.

Tabela 3. Valores das curvas de indentação associado ao trabalho realizado para o aço Inox $304 \mathrm{~L}$ e a liga $\mathrm{NiTi}$

\begin{tabular}{cccccccc}
\cline { 2 - 7 } & Condições & $\begin{array}{c}\mathbf{F}_{\max } \\
(\mathbf{m N})\end{array}$ & $\begin{array}{c}\mathbf{h}_{\max } \\
\mathbf{\mu m}\end{array}$ & $\begin{array}{c}\mathbf{h}_{\mathbf{p}} \\
\boldsymbol{\mu m}\end{array}$ & $\begin{array}{c}\mathbf{W}_{\mathbf{t}} \\
\mathbf{m N} . \boldsymbol{\mu m}\end{array}$ & $\begin{array}{c}\mathbf{W}_{\mathbf{e}} \\
\mathbf{m N} . \boldsymbol{\mu m}\end{array}$ & $\begin{array}{c}\mathbf{W}_{\mathbf{p}} \\
\mathbf{m N} . \boldsymbol{\mu m}\end{array}$ \\
\hline \multirow{3}{*}{$\begin{array}{c}\text { Aço Inox } \\
\text { 304L }\end{array}$} & $50 \mathrm{gf}-20 \mathrm{~s}$ & 502,22 & 2,59 & 2,07 & 548,84 & 117,45 & 431,39 \\
\cline { 2 - 8 } & $50 \mathrm{gf}-120 \mathrm{~s}$ & 502,20 & 2,92 & 2,07 & 660,68 & 194,22 & 466,46 \\
\cline { 2 - 8 } & $100 \mathrm{gf}-20 \mathrm{~s}$ & 980,89 & 4,11 & 3,20 & 1743,36 & 401,61 & 1341,75 \\
\cline { 2 - 8 } & $200 \mathrm{gf}-20 \mathrm{~s}$ & 1971,9 & 6,90 & 5,27 & 5711,42 & 423,82 & 5287,59 \\
\hline \multirow{4}{*}{ Liga NiTi $\mathrm{gf}-20 \mathrm{~s}$} & 502,35 & 3,73 & 1,96 & 741,15 & 352,77 & 388,37 \\
\cline { 2 - 8 } & $50 \mathrm{gf}-120 \mathrm{~s}$ & 501,96 & 3,49 & 2,11 & 732,58 & 274,73 & 457,85 \\
\cline { 2 - 8 } & $100 \mathrm{gf}-20 \mathrm{~s}$ & 990,99 & 5,74 & 2,91 & 2374,13 & 1139,11 & 1235,01 \\
\cline { 2 - 8 } & $200 \mathrm{gf}-20 \mathrm{~s}$ & 1971,62 & 11,50 & 6,31 & 11086,85 & 3950,01 & 7136,85 \\
\hline
\end{tabular}


De acordo com a Tabela 3, as amostras do aço Inox 304L e liga NiTi na condição "200 gf-20 s" tiveram o maior trabalho plástico ( $\left.\mathrm{W}_{\mathrm{p}}\right)$ em comparação com as outras três condições. Este alto valor de trabalho plástico pode estar associado aos processos de deslizamento de discordância para os dois materiais. O resultado da liga $\mathrm{NiTi}$ poderia estar, também, associado a reorientação das variantes dos grãos martensíticos formados e posterior encruamento durante a aplicação da carga, enquanto que para o aço Inox 304L poderia estar associada a encruamento da fase austenita e a transformação induzida por deformação da austenita para martensita e posteriormente o encruamento da fase martensítica. Referente ao trabalho elástico (We) a liga $\mathrm{NiTi}$, na condição 50 gf-20 s manteve o valor próximo ao trabalho plástico, evidenciando que houve uma recuperação significativa da região deformada pelo indentador após o termino da aplicação da carga, ocorrendo uma reversão significativa da transformação de fase. Já na condição 200 gf-20 s o trabalho elástico $\left(W_{e}\right)$ é quase que a metade do trabalho plástico, evidenciando pouca reversão de fases, ou seja, a martensita induzida por tensão, sofreu deformação por deslizamento de discordância, encruando-a e fixando-a no material.

$\mathrm{Na}$ Tabela 4 são mostrados os valores da medida da resistência a deformação permanente sofrida pelo material $\left(\mathrm{H}_{\mathrm{it}}\right)$ e do Módulo de Elasticidade de amostra ou fase que está sendo medida ( $\left.E_{i t}\right)$.

Tabela 4. Valores das curvas de indentação associadas a dureza da indentação e módulo de indentação para o aço Inox 304L e a liga NiTi

\begin{tabular}{|c|c|c|c|c|}
\hline & Condições & $\begin{array}{l}\text { Fmax } \\
(\mathrm{mN})\end{array}$ & $\begin{array}{c}\mathrm{H}_{\mathrm{it}} \\
\times 10^{3} \mathrm{MPa}\end{array}$ & $\begin{array}{c}E_{i t} \\
N / m^{2}\end{array}$ \\
\hline \multirow{4}{*}{$\begin{array}{l}\text { Aço Inox } \\
\text { 304L }\end{array}$} & $50 \mathrm{gf}-20 \mathrm{~s}$ & 502,22 & 3,98 & 86614,92 \\
\hline & $50 \mathrm{gf}-120 \mathrm{~s}$ & 502,20 & 3,65 & 47869,89 \\
\hline & $100 \mathrm{gf}-20 \mathrm{~s}$ & 980,89 & 3,18 & 61664,12 \\
\hline & $200 \mathrm{gf}-20 \mathrm{~s}$ & 1971,9 & 2,32 & 40429,21 \\
\hline \multirow{4}{*}{ Liga NiTi } & $50 \mathrm{gf}-20 \mathrm{~s}$ & 502,35 & 0,32 & 23792,37 \\
\hline & $50 \mathrm{gf}-120 \mathrm{~s}$ & 501,96 & 0,34 & 31206,32 \\
\hline & $100 \mathrm{gf}-20 \mathrm{~s}$ & 990,99 & 0,12 & 18677,46 \\
\hline & $200 \mathrm{gf}-20 \mathrm{~s}$ & 1971,62 & 0,01 & 10283,29 \\
\hline
\end{tabular}

$\mathrm{Na}$ Tabela 4 é mostrado que ao aumentar a carga máxima, os valores associados ao limite de escoamento $\left(\mathrm{H}_{\mathrm{it}}\right)$ e módulo de elasticidade, tanto do aço Inox $304 \mathrm{~L}$ quanto da liga $\mathrm{NiTi}$, decresceram. Para carga máxima de $50 \mathrm{gf}(490 \mathrm{mN})$, as propriedades medidas na ultramicrodureza instrumentada estão relacionadas a uma pequena população de grãos dos materiais, à medida que aumenta a carga máxima aplicada, a população de grãos é aumentada.

\section{CONCLUSÃO}

De acordo com o estudo realizado conclui-se que:

- Com o auxílio da técnica da ultramicrodureza instrumentada foi possível fazer a caracterização mecânica da fase-mãe (austenita) do aço Inox 304L e da liga NiTi rica em $\mathrm{Ni}$, e sua respectiva transformação de fase e encruamento proveniente da deformação;

- Com a avaliação dos gráficos gerados, foi observado uma significativa recuperação elástica da liga $\mathrm{NiTi}$; 
- Os tempos de estabilização 20 s e 120 s, sob mesma carga (50 gf-490 mN), não foram suficientes para estabilizar a deformação nos materiais estudados;

- As durezas dinâmicas elasto-plástica (DHV-1) e plástica (DHV-2) decresceram com o aumento da carga máxima, pois quanto maior a carga aplicada leva uma redução dos valores das durezas dinâmicas;

- Referente ao trabalho elástico $\left(\mathrm{W}_{\mathrm{e}}\right)$, a liga NiTi apresentou uma recuperação significativa em cargas menores e em deformações maiores houve deslizamento de discordância, encruando-a e fixando-a no material. Para o aço Inox 304L houve uma pequena variação;

- Este tipo de ensaio se mostrou mais efetivo em elucidar o comportamento mecânico deste tipo de materiais susceptíveis a transformação de fase quando deformados do que o ensaio de dureza convencional associado aos valores de tão somente a dureza HV.

\section{Agradecimentos}

Os autores agradem ao Laboratório de Multiusuário de Caracterização de Materiais do Instituto de Ciências Exatas (ICEx) da Universidade Federal Fluminense (UFF) pela disponibilizam do ultramicrodurômetro Shimadzu DUH-211S para este estudo. Os autores F. S. Assis e A. C. Pereira agradecem a CAPES pela bolsa de mestrado. A autora A. S. Paula agradece ao CNPq pela bolsa de produtividade nível 2 (Processo 307798/2015-1).

\section{REFERÊNCIAS}

1 H. Funakubo, Shape Memory Alloys - Precision Machinery and Robotics, Volume 1, Versão Inglesa traduzida do Japonês por J.B. Kennedy, Gordon and Breach Science Publishers, 1987.

2 Paula AS. Tratamentos Termomecânicos de Ligas do Sistema Ni-Ti. Caracterização Estrutural e Optimização das Propriedades Associadas ao Efeito de Memória de Forma. Tese de doutorado, Programa de Pós-Graduação em Engenharia dos Materiais e Ciência dos Materiais, Universidade Nova de Lisboa, Lisboa, Portugal, 2006.

3 Alves JM. Análise da transformação martensítica e tensão residual em um aço inoxidável 304L, Dissertação de Mestrado, Programa de Pós-Graduação em Ciência dos Materiais, Instituto Militar de Engenharia, Rio de Janeiro, Brasil, 2014.

4 Vieira TF. Caracterização microestrutural de aço inox austenítico 304L, Projeto de Graduação, Curso de Engenharia Metalúrgica, Universidade Estadual Fluminense, Volta Redonda, Brasil, 2011.

5 Diniz et.al., A utilização da nanoindentação instrumentada para caracterização de materiais metálicos. $70^{\circ}$ Congresso Anual da ABM. Rio de Janeiro, Brasil, 2015.

6 Shimadzu dynamic ultra-micro hardness tester DUH-211/ DUH-211S Instruction manual, Shimadzu Corporation, Japan, 2009."

7 Paula AS., Fernandes FMB. Nano-indentation in Ti-rich Ni-Ti SMA at room temperature in different structural conditions. $63^{\circ}$ Congresso Anual da ABM. Santos, SP, Brasil, 2008. 